\title{
Community Based Cross- Sectional Study to Assess the Utilization Pattern of Antenatal Health Care Services among Married Women of Reproductive Age Group in a Rural Area of Bihar
}

\author{
Arvind Kumar Vimal', Pankaj Kumar² \\ ${ }^{1}$ Assistant Professor, Department of Community Medicine/ PSM, Government Medical College, Bettiah, Bihar, ${ }^{2}$ Tutor, Department of Community Medicine/ PSM, \\ Government Medical College, Bettiah, Bihar.
}

\section{Abstract}

Background: ANC services is important to ensure safe motherhood. The present study was conducted to assess the utilization of ANC services in rural area. Subjects and Methods: The present study was community based cross-sectional in nature conducted upon 180 currently married women having children of less than one year of age and living in the area covered by rural training center of the institute. Sociodemographic profile and details of utilization of ANC services were noted. Results: Most of the respondents belonged to the age group of 20-30 years. $37.2 \%$ of them were illiterate and 58.9\% lived in nuclear family. $53.9 \%$ had institutional delivery and $42.2 \%$ had more than two children. $42.8 \%$ of mothers registered their pregnancy before 12 weeks. Only $17.2 \%$ mothers had four or more ANC visits. $87.2 \%$ of them were fully immunized against tetanus but only $11.1 \%$ consumed 100 or more IFA tablets. Lack of awareness was responsible in $28.2 \%$, lack of transport in $16.8 \%$, unwillingness in $34.2 \%$ and other reasons in $20.8 \%$ cases among the mothers not utilizing ANC services properly. Conclusion: Utilization of ANC services is poor in this area.

Keywords: ANC services, Cross-sectional study, Utilization.

Corresponding Author: Dr. Pankaj Kumar, Tutor, Department of Community Medicine/ PSM, Government Medical College, Bettiah, Bihar. Email:drpklal@gmail.com

Received: November 2019

Accepted: December 2019

Introduction

It has been estimated that every year, 5 lakh women die globally as a result of pregnancy and childbirth worldwide. It has been found that about $88 \%-98 \%$ of these deaths are preventable by proper care and handling during pregnancy and labour. ${ }^{[1]} 50$ million women in India suffer from maternal morbidity due to acute complications from pregnancy.

Quality antenatal, intranatal, and postnatal care is the single most important factor to prevent maternal and infant morbidity and mortality. WHO has recommended a minimum of four antenatal care (ANC) visits to ensure safe motherhood. ${ }^{[2]}$

However, utilization of maternal healthcare services is low. In India more than one in five mothers received no antenatal care. Almost two-thirds of women in Bihar did not receive any antenatal care. Common reasons include high illiteracy among females, early marriages, ignorance, low quality as well as high cost of service, social structure, detrimental health beliefs, personal characteristics, and malnutrition. ${ }^{[3]}$ Various authors have explored the factors associated with poor utilization of maternal healthcare services. ${ }^{[4-11]}$ No such study has been conducted in this area. Hence, the present study was proposed.

\section{$\underline{\text { Aims \& Objectives }}$}

The present study was conducted to assess the utilization of ANC services in rural area of Bettiah, Bihar.

\section{Subjects and Methods}

\section{Study setting:}

The present study was conducted at the Department of PSM, Government Medical College, Bettiah, Bihar. The institute caters to population of West Champaran and adjoining area of Nepal.

\section{Study Design:}

The present study was community based cross-sectional in nature.

\section{Study subjects:}

Study subjects included currently married women having children of less than one year of age.

\section{Inclusion criteria:}

The currently married women having children of less than one year of age and living in the area covered by rural training center of the institute were included in the present study. 


\section{Exclusion criteria:}

Seriously ill patients and those who refused to give consent were excluded.

\section{Sampling:}

Sample size was calculated using the formula

Sample size $=4 \mathrm{pq} / \mathrm{d}^{2}$

NFHS-4 reported that $13 \%$ women had minimum four ANC in rural areas of Bihar. ${ }^{[3]}$ Considering precision of $5 \%$, the sample size was calculated to be 180 . Thirty AWCs were randomly selected and from each, 6 mothers were randomly included.

\section{Data collection procedure:}

CDPO of the block was informed and consent was taken. AWCs were approached and informed about the study and their help was taken. Pre-tested proforma was used for data collection which included questions regarding background information and details of ANC.

\section{Data analysis:}

Data was entered in Microsoft Excel and analyzed using SPSS software. Percentage, proportions and contingency tables were used for description of the data. $\mathrm{P}$ value $<0.05$ was considered as statistically significant.

\section{Ethical consideration \& permission:}

Approval from Institutional Ethics Committee was obtained. Informed consent was taken from the patients. Confidentiality of records was maintained.

\section{Results}

A total of 180 subjects were included in the present study. [Table 1] shows sociodemographic details. Most of the respondents belonged to the age group of 20-30 years. $37.2 \%$ of them were illiterate and $58.9 \%$ lived in nuclear family. 53.9\% had institutional delivery and $42.2 \%$ had more than two children.

\begin{tabular}{|c|c|c|}
\hline Sociodemographic factor & Frequency & $\%$ \\
\hline$<20$ & 29 & 16.1 \\
\hline $20-30$ & 112 & 62.2 \\
\hline$>30$ & 22 & 12.2 \\
\hline Illiterate & 67 & 37.2 \\
\hline Primary & 52 & 28.9 \\
\hline Secondary and above & 61 & 33.9 \\
\hline Hindu & 146 & 81.1 \\
\hline Muslim & 34 & 18.9 \\
\hline Nuclear & 106 & 58.9 \\
\hline Joint & 74 & 41.1 \\
\hline Institutional & 97 & 53.9 \\
\hline Home & 83 & 46.1 \\
\hline$<2$ & 104 & 57.8 \\
\hline$>2$ & 76 & 42.2 \\
\hline
\end{tabular}

[Table 2] shows the utilization of ANC services. $42.8 \%$ of mothers registered their pregnancy before 12 weeks. Only $17.2 \%$ mothers had four or more ANC visits. $87.2 \%$ of them were fully immunized against tetanus but only $11.1 \%$ consumed 100 or more IFA tablets.

\begin{tabular}{l|l|l|}
\hline \multicolumn{3}{l}{ Table 2: showing utilization of ANC services } \\
\hline ANC Services & Frequency & $\%$ \\
\hline Registration of pregnancy & & \\
$-<12$ weeks & 77 & 42.8 \\
$-12-24$ weeks & 65 & 36.1 \\
$->24$ weeks & 38 & 21.1 \\
\hline No. of ANC visits & & \\
-Nil & 34 & 18.9 \\
$-1-3$ & 115 & 63.9 \\
$->3$ & 31 & 17.2 \\
\hline TT immunization & 5 & \\
Nil & 18 & 2.8 \\
Partial & 157 & 10 \\
Fully immunized & & 87.2 \\
Consumption of IFA tablets & 40 & \\
Nil & 121 & 67.2 \\
$<100$ & 20 & 11.1 \\
100 and above &
\end{tabular}

[Table 3] shows the reasons behind non-utilization of ANC services. Lack of awareness was responsible in $28.2 \%$, lack of transport in $16.8 \%$, unwillingness in $34.2 \%$ and other reasons in $20.8 \%$ cases among the mothers not utilizing ANC services properly.

Table 3: showing reasons behind non-utilization of ANC services $(n=149)$

\begin{tabular}{|l|l|l|}
\hline Reason & Frequency & \% \\
\hline Not knowing & 42 & 28.2 \\
\hline Not willing & 51 & 34.2 \\
\hline No transport & 25 & 16.8 \\
\hline Others & 31 & 20.8 \\
\hline
\end{tabular}

\section{Discussion}

Antenatal care services are one of the key components of $\mathrm{MCH}$ services for ensuring safe motherhood and healthy newborn and infants. Poor utilization of these lead to delay in identification of high-risk cases and further morbidity and mortality.

The present study included 180currently married women having children of less than one year of age and living in the area covered by rural training center. Most of the respondents belonged to the age group of 20-30 years. $37.2 \%$ of them were illiterate and $58.9 \%$ lived in nuclear family. 53.9\% had institutional delivery and $42.2 \%$ had more than two children. Kakati et al found that $79.6 \%$ mothers belonged to Hindu religion and most of them (46.6\%) belonged to OBC categories. Most of the women (66\%) lived in nuclear families. Almost 50\% of mothers were in the age group of $26-30$ years. $17.6 \%$ were illiterate, $21.6 \%$ had attended primary school, 23.4\% had attended middle school, $10.6 \%$ had attended higher secondary school and only $3.6 \%$ were graduate. Majority (53.3\%) of mothers, house wife by occupation followed by $21 \%$ cultivators and $12.3 \%$ daily wage earners. ${ }^{[1]}$ Murthy et al found that $88.5 \%$ were in 20-34 years age group. Teenage pregnancies were $54 \%$. $88.5 \%$ were housewives and $11.5 \%$ were working mothers (maximum was coolie workers). $84.5 \%$ women were literates. $75.5 \%$ husbands were literates. $80 \%$ mothers 
were staying in joint family. ${ }^{[7]}$

$42.8 \%$ of mothers registered their pregnancy before 12 weeks. Only $17.2 \%$ mothers had four or more ANC visits. $87.2 \%$ of them were fully immunized against tetanus but only $11.1 \%$ consumed 100 or more IFA tablets. Kakati et al found that all (100\%) the women were registered during the antenatal period and among them 53\% were registered during first trimester and $45 \%$ were registered during second trimester. Among the registered women $68.7 \%$ had more than three antenatal visits followed by $31.3 \%$ had less than three antenatal visits. Majority of the women $(90 \%)$ were fully immunized with TT vaccine followed by $8 \%$ were partially immunized i.e., received only one dose of TT vaccine. $71.6 \%$ of women consumed 100 or more IFA tablets followed by $26.3 \%$ of women received $<100$ IFA tablets. $73 \%$ of women in the age group of 19-30 years had adequate ANC followed by $56.8 \%$ of women in the age group of $<19$ years had adequate ANC and $42 \%$ of women in the age group of $>30$ years had adequate ANC ${ }^{[1]}$ Murthy et al found that $90 \%$ mothers had undergone more than 3 ANC check-ups. All women had taken TT injection and IFA tablets. 94\% mothers had consumed more than 100 IFA tablets during pregnancy. Women who were not taking IFA tablets regularly were due to vomiting $(58.33 \%)$ and abdominal discomfort (41.67\%). ${ }^{[7]}$

Lack of awareness was responsible in $28.2 \%$, lack of transport in $16.8 \%$, unwillingness in $34.2 \%$ and other reasons in $20.8 \%$ cases among the mothers not utilizing ANC services properly. Kakati et al found that among the women who did not attend the ANC, $26.7 \%$ of women were reported being residence in remote areas followed by $22.6 \%$ were reported of unwillingness of ANC. Among them $21.6 \%$ of women were not aware about the need of antenatal care services and $18.6 \%$ had reported with difficulty in transportation. ${ }^{[1]}$ On enquiring about the reasons for inadequate utilization of ANC services, Shora et al found that the three major responses were nonawareness, financial constraints and non-availability of transport facilities. ${ }^{[2]}$

\section{Conclusion}

The present study found that utilization of ANC services was inadequate in this area. Only $42.8 \%$ of mothers registered their pregnancy before 12 weeks and only $17.2 \%$ mothers had four or more ANC visits. There is need to create awareness regarding importance of these services to improve the situation.

\section{References}

1. Kakati R, Barua K, Borah M. Factors associated with the utilization of antenatal care services in rural areas of Assam, India. Int J Community Med Public Health 2016:2799-805.

2. Shora T, Verma A, Jan R, Gupta R. Knowledge regarding antenatal care services, its utilization, and delivery practices in mothers (aged 15-49 years) in a rural area of North India. Trop J Med Res 2015;18:89.

3. Dehury RK. Maternal Health Situation in Bihar and Madhya Pradesh: A Comparative Analysis of State Fact Sheets of National Family Health Survey (NFHS)-3 and 4. JCDR 2016;8:92-9.

4. Brahmapurkar K. Poor Maternal Heath Care in Rural Districts: An Attempt to Identify High Priority Districts of Bihar, India. National J Community Med 2017;8:79-83.

5. Adhikari T, Sahu D, Nair S, Saha K, Sharma R, Pandey A. Factors associated with utilization of antenatal care services among tribal women: A study of selected States. Indian J Med Res 2016;144:58.

6. Kapoor SK, Reddaiah VP, Lobo J. Antenatal care and perinatal mortality. Indian J Pediatr 1985;52:159-62.

7. Siddalingappa H, Mishra B. Assessment of utilization of antenatal care services by mothers attending immunization sessions at a primary health centre in Mysore district, Karnataka, India. Int J Community Med Public Health 2016:2561-5.

8. Ponna S, Upadrasta V, Babu Geddam J, Dudala S, Sadasivuni R, Bathina H. Regional variation in utilization of Antenatal care services in the state of Andhra Pradesh. J Family Med Prim Care 2017;6:231.

9. Bhimani N, Vachhani P, Kartha G. Utilization pattern of antenatal health care services among married women of reproductive age group in the rural area of Surendranagar district, Gujarat, India: a community based cross sectional study. Int J Res Med Sci 2016;9:252-61.

10. Matthews Z, Mahendra S, Kilaru A, Ganapathy S. Antenatal care, care-seeking and morbidity in rural Karnataka, India: Results of a prospective study. Asia-Pacific Population J 2001;16:11-28.

11. Shekhawat R, Sharma N, Kashyap A, Sodha VS. Utilization of Antenatal Care Services and Its Determinants in Rural Field Practice Area of Jaipur. India 2018;9:4-10.

Copyright: (c) the author(s), 2020. It is an open-access article distributed under the terms of the Creative Commons Attribution License (CC BY 4.0), which permits authors to retain ownership of the copyright for their content, and allow anyone to download, reuse, reprint, modify, distribute and/or copy the content as long as the original authors and source are cited.

How to cite this article: Vimal AK, Kumar P. Community Based Cross- Sectional Study to Assess the Utilization Pattern of Antenatal Health Care Services among Married Women of Reproductive Age Group in a Rural Area of Bihar. Asian J. Med. Res. 2020;9(1):CM01-CM03.

DOI: dx.doi.org/10.47009/ajmr.2020.9.1.CM1

Source of Support: Nil, Conflict of Interest: None declared. 